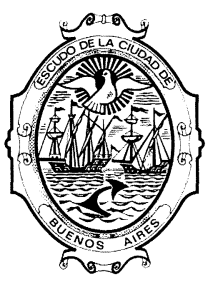

\title{
AUTOPISTAS:
}

\section{AU-1 25 DE MAYO y AU-6 PERITO MORENO}

\section{Buenos Aires - Rep. Argentina}

$513-22$

\section{SINOPSIS}

Las autopistas $A U-1$ y $A U-6$, con una longitud aproximada de $17 \mathrm{~km}$, se realizaron con objeto de resolver el grave problema de infraestructura vial del Municipio de Buenos Aires, ciudad de nueve millones de habitantes y con un parque de vehículos en rápido crecimiento.

Para el proyecto se creó un programa de ordenador con el que, partiendo de la definición geométrica de la autopista y de la posición de las pilas, se calculan todos los elementos que componen la estructura y se dimensionan las armaduras. Este programa permitió proyectar un tramo $(150 \mathrm{~m})$ por semana.

La construcción, a un ritmo muy rápido, se llevó a cabo mediante cimbras autoportantes compuestas por vigas metálicas apoyadas sobre ménsulas, las cuales a su vez apoyan en unos nichos dejados en las pilas.

La Municipalidad de la Ciudad de Buenos aires, consciente del grave problema de infraestructura vial en la zona del Gran Buenos Aires donde habitan nueve millones de personas y existe un parque de vehículos en rápido crecimiento, abordó con el apoyo del Gobierno de la Nación la realización del Plan de Autopistas Urbanas en régimen de peaje.

Unicamente los apoyos de las articulaciones de media madera, se realizan con neopreno-teflón. Esta solución es mucho mejor que utilizar apoyos de neopreno-tefión en las pilas, lo que sería necesario en caso de realizar tramos más largos.

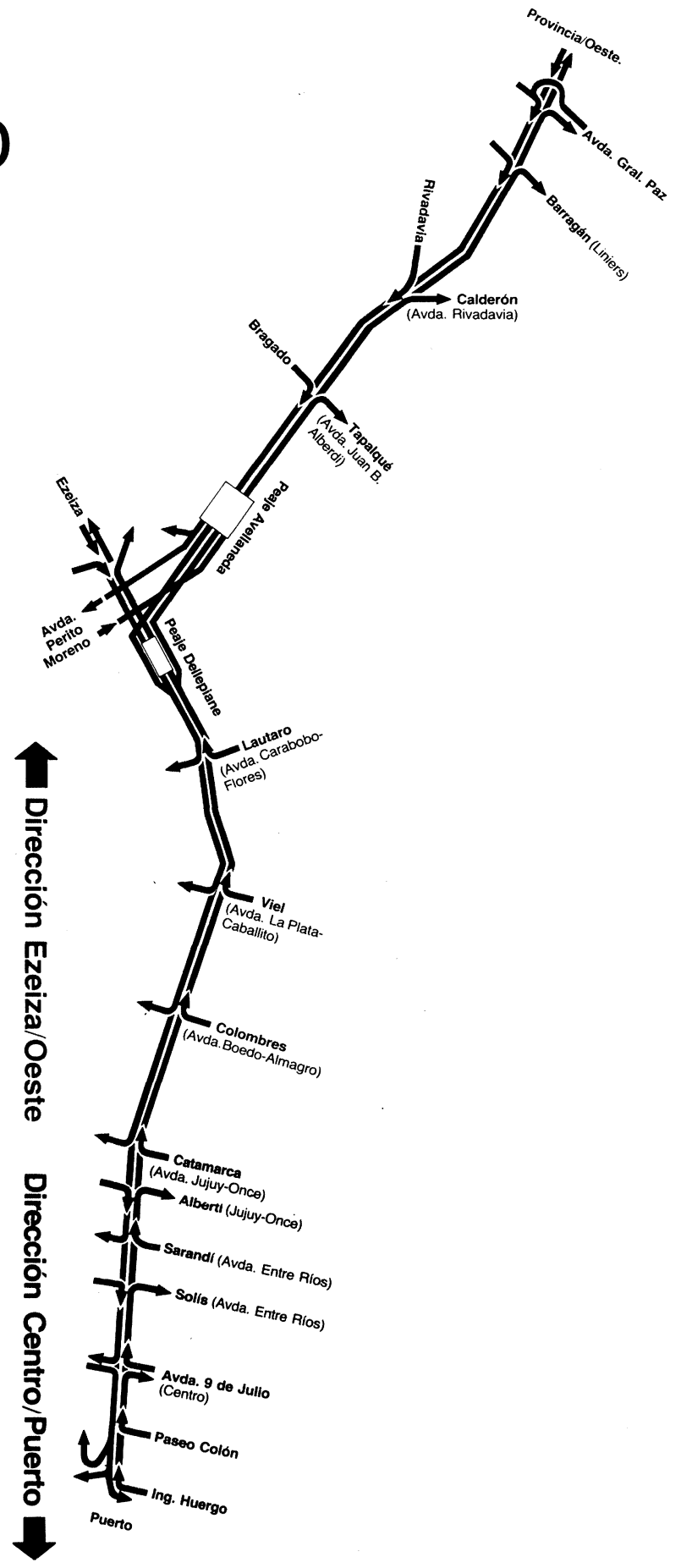

planta general (salidas y accesos) 


\section{construcción}

La construcción se realizó mediante cimbras autoportantes, una por cada cajón, con un frente de cuatro cimbras.

El conjunto de la obra constaba de ocho frentes con un total de 32 cimbras.

La cimbra autoportante se componia de dos vigas metálicas apoyadas sobre unas consolas, que a su vez lo hacen en unos nichos dejando en las pilas.

El movimiento de las cimbras se realizó mediante gatos hidráulicos horizontales y una vez en su posición, se apoyaban sobre gatos verticales que permitian una perfecta nivelación de la cimbra y un movimiento vertical en el momento de desencofrar el vano ya construido.

El encofrado de madera se apoyó sobre vigas metálicas. El fondo, es abatible, para poder pasar por las pilas en el movimiento de la cimbra.

Desde el otoño de 1976 y en el breve plazo de un año, la Municipalidad desarrolló una intensa actividad técnica, legal y administrativa, con la complejidad que esto supone, con el fin de conseguir la realización de la Autopista 25 de Mayo AU-1 y el ramal de la Autopista Perito Moreno AU-6.

Mediante Concurso Internacional, se adjudicó la construcción y explotación de las autopistas al Consorcio integrado por empresas nacionales $y$ extranjeras que con fecha 17 de enero de 1978 formaron la sociedad concesionaria Autopistas Urbanas, S. A. -AUSA-.

Las obras se iniciaron en noviembre de 1978 y terminaron el mismo mes de 1980.

\section{planteamiento general}

El conjunto de estas dos autopistas urbanas tiene una longitud aproximada de $17 \mathrm{~km}$ de los que 15 están realizados en viaducto elevado para no obstaculizar el tráfico por las calles de la zona y con ocho carriles de circulación, lo que hace necesario un ancho total de plataforma de $36,8 \mathrm{~m}$.

La gran envergadura de este viaducto de más de medio millón de metros cuadrados, sumado a un corto plazo de ejecución - de dos años- obligaron a plantear una industrialización máxima de la obra.

La industrialización en la construcción de puentes puede hacerse, LLEVANDO LA OBRA AL TALLER, con la PREFABRICACION de la estructura de hormigón y transportando los elementos prefabricados para su colocación en obra, o LLEVANDO EL TALLER A LA OBRA, creando un taller móvil que vaya realizando los distintos elementos en su posición definitiva trasladándose posteriormente para continuar el proceso. El taller está compuesto por una cimbra autoportante y una nave móvil que se apoyan en las pilas del puente y se desplazan longitudinalmente. Esto permite la construcción bajo cubierta y prefabricar la armadura de un vano sobre el otro anterior y transportarlo posteriormen-

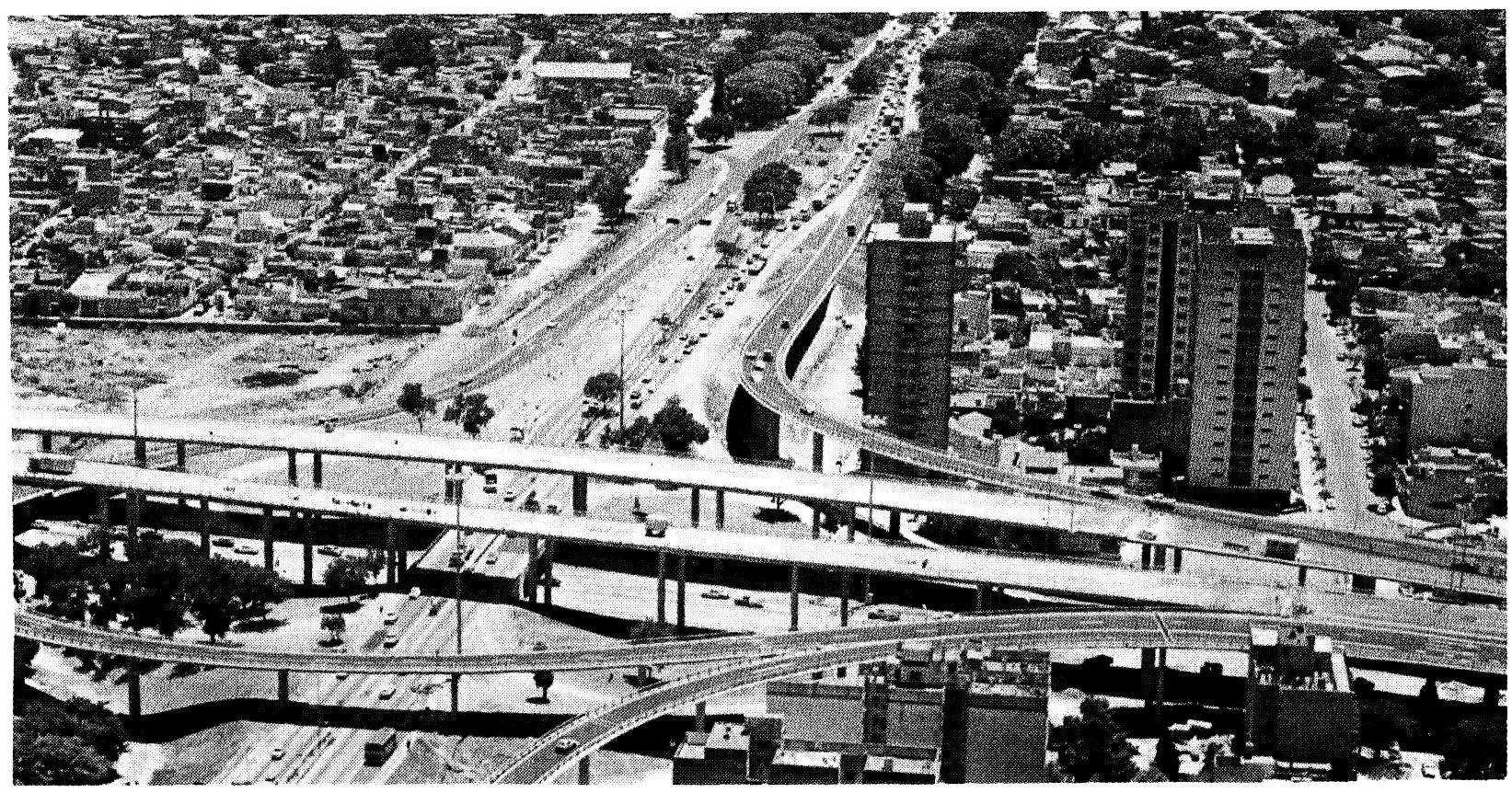




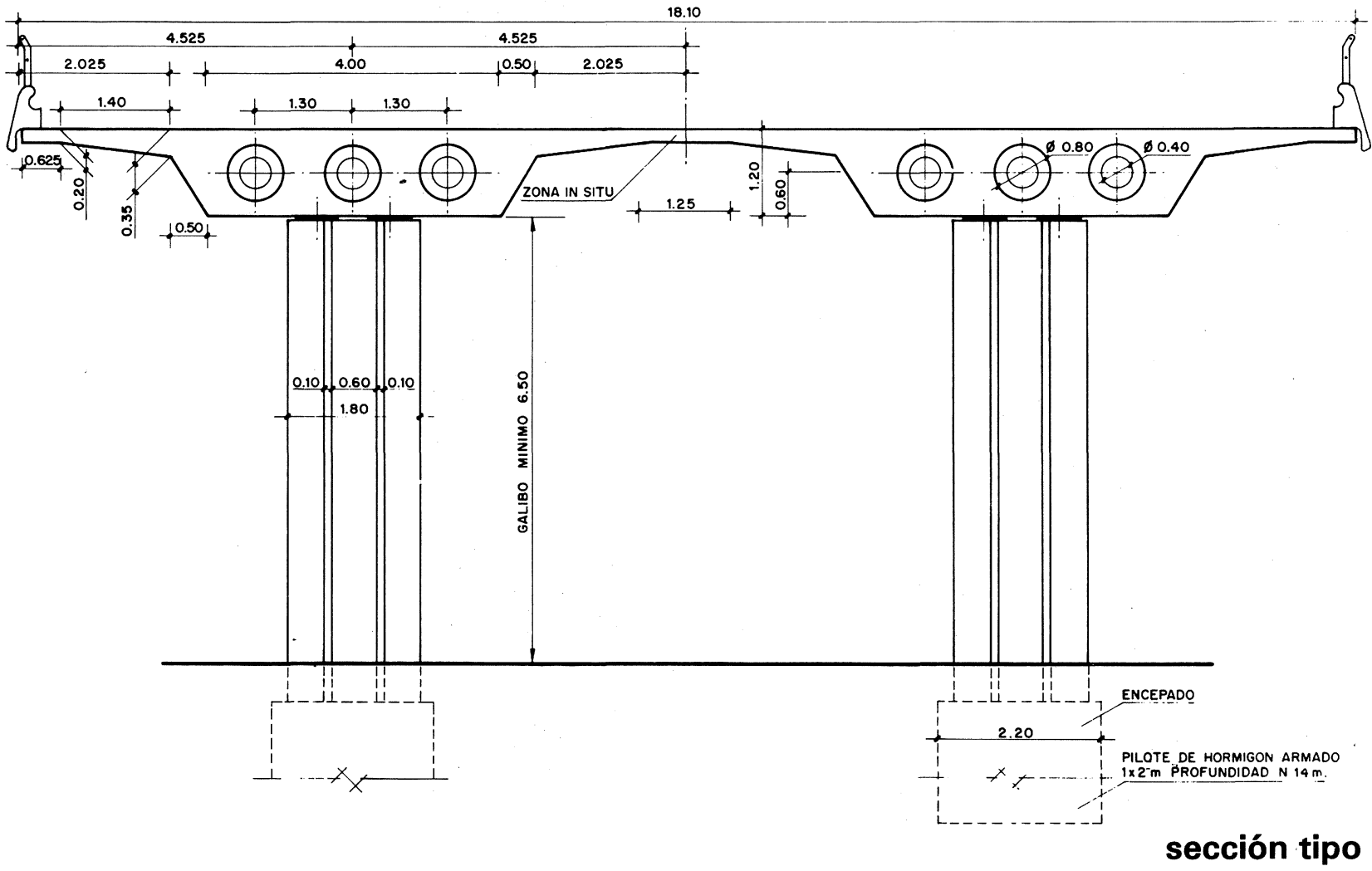

te a su posición definitiva mediante otro desplazamiento longitudinal de la nave.

La autopista de Buenos Aires requiere un viaducto de poca altura, porque únicamente es necesario permitir el gálibo de tráfico de las calles inferiores. Teniendo en cuenta el ancho de las calles a cruzar, las luces más adecuadas varian entre los 20 y 30 metros.

En nuestro caso, son aplicables ambas soluciones de industrialización, pero se decidió como más conveniente la construcción in situ mediante cimbras por dificultades de transporte, variación de luces, alturas, trazado y agilidad en el desarrollo general de la obra.

\section{proyecto}

Los condicionantes del trazado y de las calles de la ciudad, que aun estando dispuestas en una cuadrícula bastante regular no mantienen distancias iguales, imposibilitaron la repetición del proyecto, pues además, los cien tramos en que se divide la autopista son todos distintos y en muchas ocasiones también distintas ambas calzadas.

Por esta razón fue necesario crear un programa de ordenador, que partiendo de la definición geométrica del eje de la autopista y de la posición de las pilas del tramo, genera el modelo matemático de cálculo y estudia todos los elementos que componen la estructura y dimensiona las armaduras. Unicamente es necesario introducir el trazado de la armadura de pretensado una vez que el programa ha obtenido los esfuerzos exteriores.

En este programa es necesario considerar varios modelos distintos de la estructura:

1. ${ }^{-L a}$ estructura terminada para el estudio de la actuación de la sobrecarga. Se ha utilizado un modelo de emparrillado espacial considerando los dos cajones principales, la losa de conexión, las pilas y las cimentaciones. En el caso de incorporación de rampas es necesario considerar los tres cajones, lo que complica el modelo de cálculo.

2. La estructura durante el proceso constructivo, que es totalmente distinta, ya que se construyen los dos cajones independientemente, varía en cada etapa de construcción, pues las acciones de peso propio y pretensado de cada vano, actúan en el momento de descimbrar sobre la estructura parcial construida hasta ese momento.

Este programa ha permitido realizar el proyecto de un tramo por semana, es decir, unos $150 \mathrm{~m}$ de longitud de tablero con los elementos siguientes: 


\section{cimentaciones}

La cimentación se realizó con pilotes semiprofundos en forma semirrectangular. Se prefirió esta solución a la cimentación directa por razones de rapidez de ejecución, menor perturbación superficial y menor volumen de excavación, consiguiendo mayor seguridad frente a posibles alteraciones superficiales para obras futuras o, cambios de servicios.

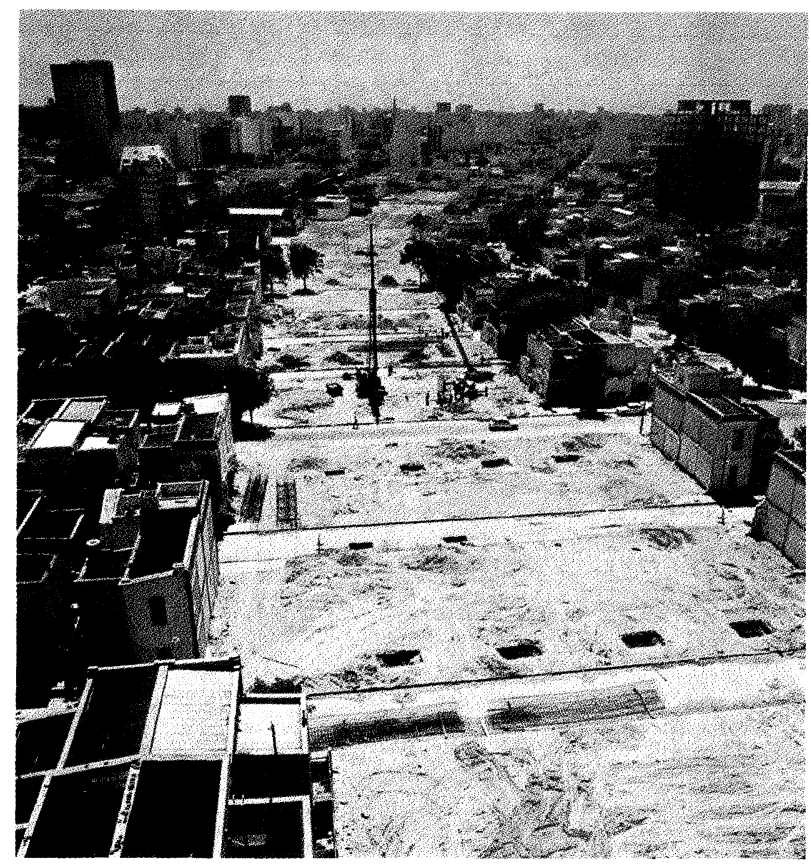

\section{pilas}

Cada uno de los pilotes se prolonga en una pila de sección también semirrectangular. En cada línea transversal de apoyo, se colocan cuatro pilas separadas entre sí unos 9 metros.

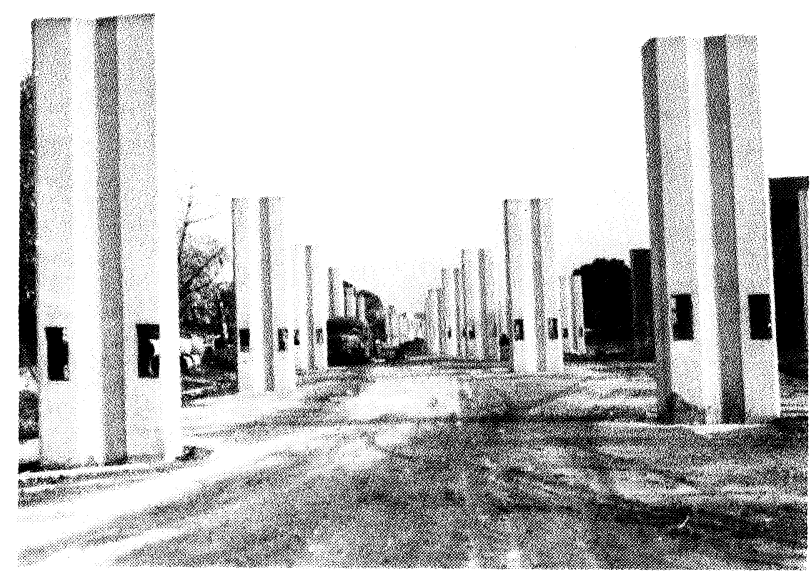

\section{tablero}

Sobre cada una de las pilas se apoya un cajón de forma trapecial, aligerado interiormente mediante tres alveolos circulares.

Cada uno de estos cajones se construye independientemente mediante la cimbra autoportante, empalmándose con posterioridad los vuelos de cada dos cajones y dejándose la mediana abierta.

En sentido longitudinal el tablero es una viga continua dividida en tramos de aproximadamente 150 metros de longitud, empalmando con el tramo siguiente, mediante una articulación a media madera, a los 2/9 de la luz del vano de unión de los tramos. Esta solución produce una distancia entre juntas de pavimento, adecuada para una buena rodadura, sin hacerlas excesivamente costosas. Permite además realizar todos los apoyos del tablero sobre pilas mediante neopreno.

Unicamente los apoyos de las articulaciones de media madera, se realizan con neopreno-teflón. Esta solución es mucho mejor que utilizar apoyos de neopreno-teflón en las pilas, lo que seria necesario en caso de realizar tramos más largos.

\section{construcción}

La construcción se realizó mediante cimbras autoportantes, una por cada cajón, con un frente de cuatro cimbras.

El conjunto de la obra constaba de ocho frentes con un total de 32 cimbras.

La cimbra autoportante se componia de dos vigas metálicas apoyadas sobre unas ménsulas, que a su vez lo hacen en unos nichos dejados en las pilas.

El movimiento de las cimbras se realizó mediante gatos hidráulicos horizontales y una vez en su posición, se apoyaban sobre gatos verticales que permitian una perfecta nivelación de la cimbra y un movimiento vertical en el momento de desencofrar el vano ya construido.

El encofrado de madera se apoyó sobre vigas metálicas. El fondo, es abatible, para poder pasar por las pilas en el movimiento de la cimbra.

Sobre la cimbra se montaron unas naves móviles mediante ruedas sobre vias, que permiten construir a cubierto y prefabricar la armadura de una fase, sobre la anterior, transportándola colgada de la nave a su posición definitiva. 


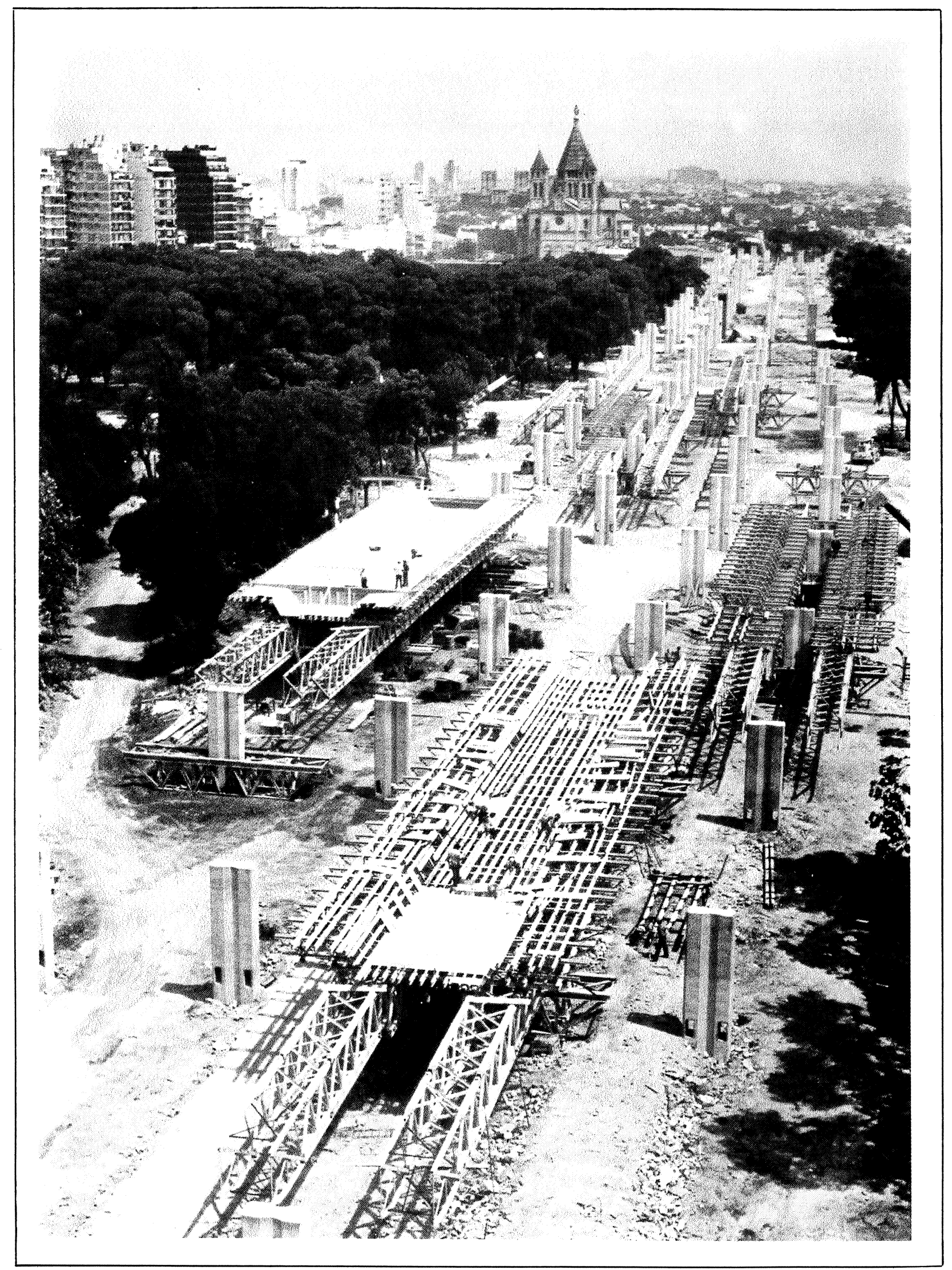

El ritmo normal de la construcción de una fase, es de cuatro dias. Las operaciones son las siguientes:

Dia 1. Traslado de la cimbra y traslado de la armadura.
Día 2. Terminación de la armadura y hormigonado.

Día 3. Endurecimiento del hormigón.

Día 4. Endurecimiento del hormigón y tensado de los cables de pretensado. 


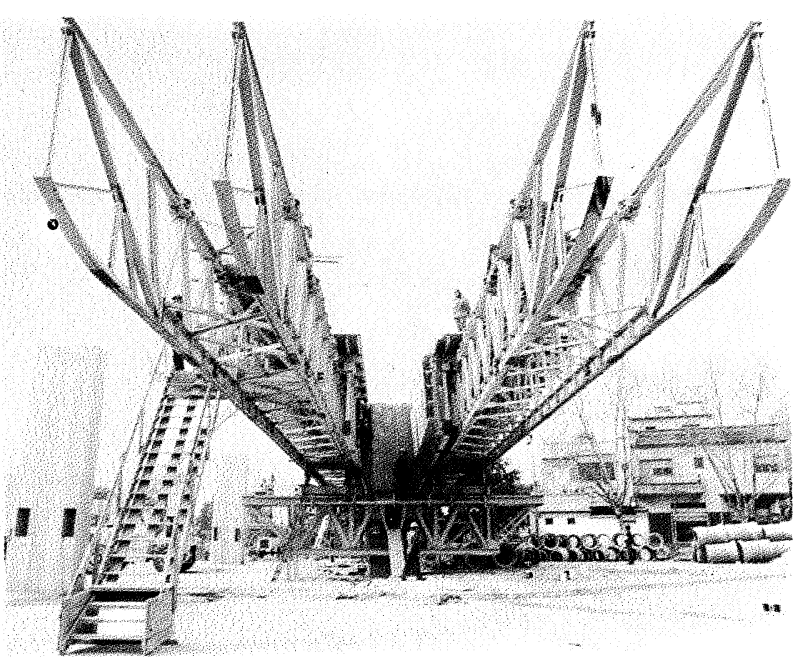

Durante estos dias se prefabrica la armadura de la fase siguiente.

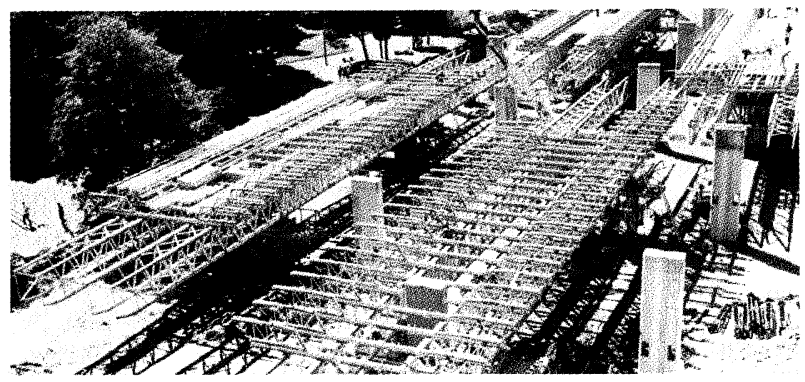

Los aligeramientos circulares de los cajones, se realizaron mediante tubos de goma hinchable, que una vez endurecido el hormigón, se deshinchan y se sacan evitando dejar un encofrado perdido.

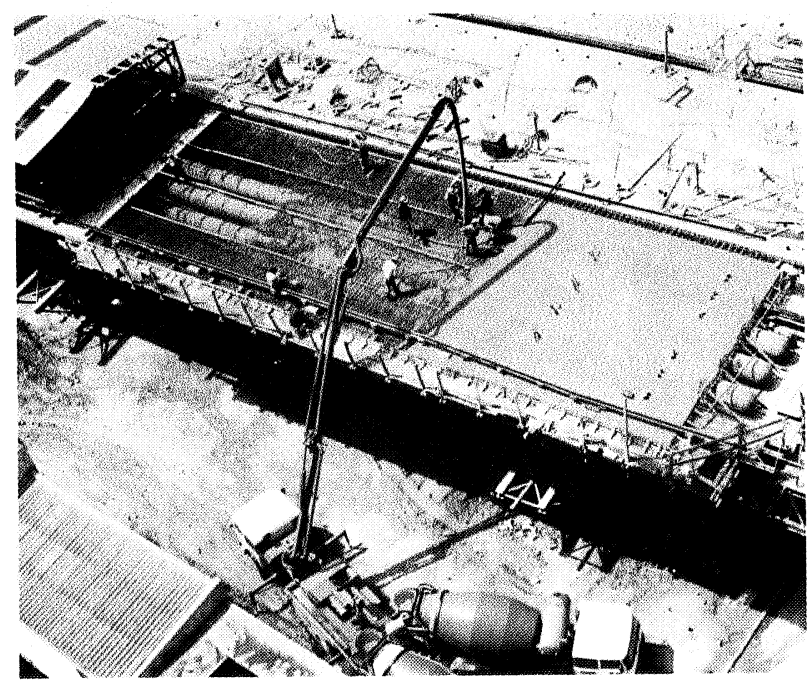

(C) Consejo Superior de Investigaciones Científicas

Licencia Creative Commons 3.0 España (by-nc)

\section{obras especiales}

Además de la autopista, ha sido necesario realizar numerosas obras adicionales. El criterio que se ha seguido en todas ellas, es el de una máxima homogeneidad con el viaducto.

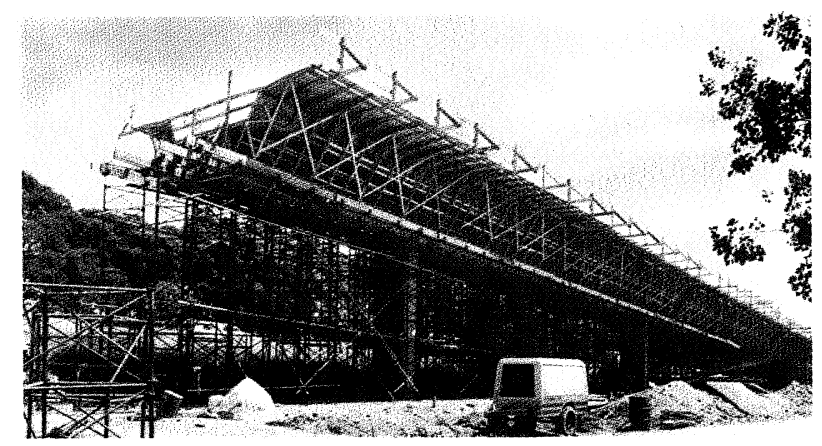

\section{a. Rampas de acceso}

Existe a lo largo de la autopista una serie de rampas de entrada y salida paralelas a la misma. Se realizaron con un cajón del mismo tipo que los del tronco, aunque más estrechos por ser menor su plataforma. La construcción se realizó con cimbra tradicional.

\section{b. Pérgola sobre el ferrocarril}

El paso sobre el ferrocarril, con una oblicuidad muy grande, planteó un problema que no pudo resolverse con la solución normal, pues la luz oblicua es mucho mayor que las posibilidades máximas de la solución general del viaducto. Por tanto se resolvió mediante una pérgola de vigas normales al ferrocarril, apoyadas sobre dos vigas transversales enlazadas a la estructura de la autopista. Estas vigas se prefabricaron en un taller fijo y se montaron mediante grúa.

\section{c. Distribuidores}

\section{Distribuidores de General Paz y 9 de Julio}

En estos dos distribuidores, existen una serie de ramales que parten de la autopista y enlazan con otras inferiores, produciéndose nudos a tres niveles. Estos ramales se realizaron con la misma solución de viga continua, pero con un solo cajón. 
Si el ramal es de dos carriles, se emplea el mismo ancho utilizado en la autopista y si es de un solo carril, el de las rampas de acceso. La solución de pilas y cimientos es también la misma.

d. Existieron también una serie de obras en la zona de tierra y en el enlace de las autopistas.

Las autopistas disponen de todos los servicios y asistencias que especifican las normas internacionales.

Superando toda clase de dificultades, se consiguió terminar la obra en el plazo previsto y fue inaugurada oficialmente el 6 de diciembre de 1980 .

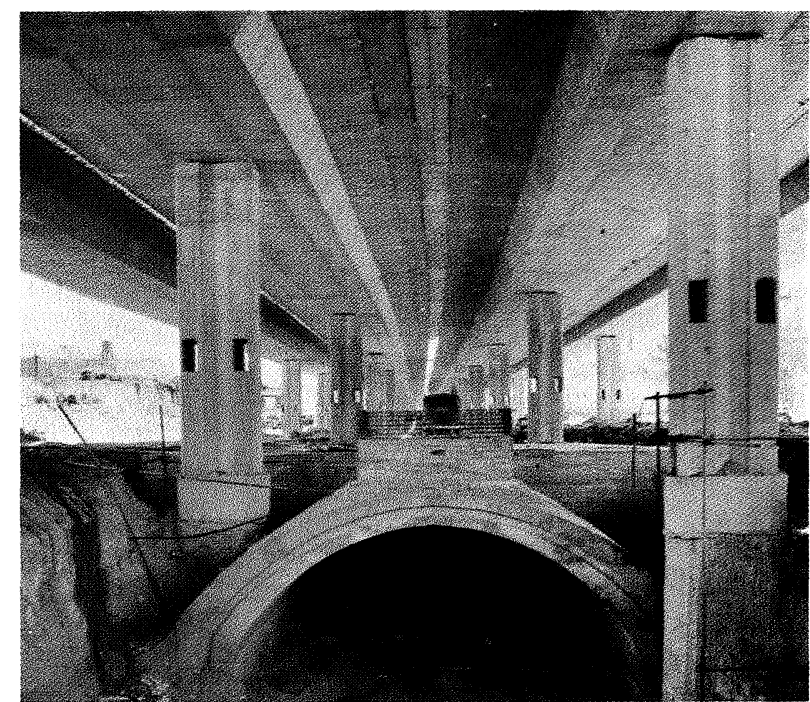

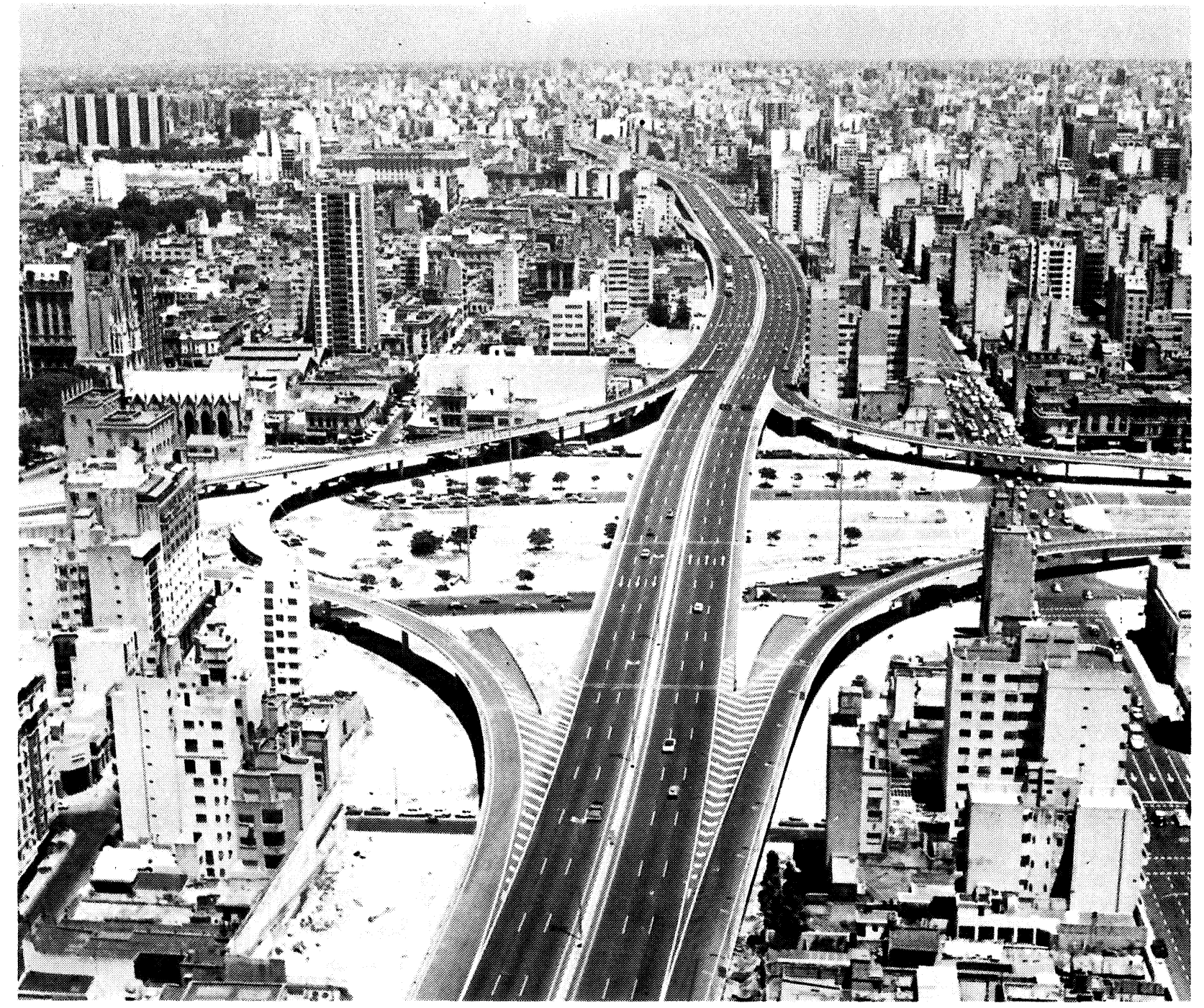

proyecto:

Carlos Fernández Casado, S. A.

EYSER. Estudios y Servicios

VYESA. Viales y Estacionamientos, S. A.

Empresa Constructora:

Huarte y Compañia, S. A. 